\title{
Design for the Damping of a Railway Collector Based on the Application of Shape Memory Alloys
}

\author{
M. Bocciolone, ${ }^{1}$ M. Carnevale, ${ }^{1}$ A. Collina, ${ }^{1}$ N. Lecis, ${ }^{1}$ A. Lo Conte, ${ }^{1}$ B. Previtali, ${ }^{1}$ \\ C. A. Biffi, ${ }^{2}$ P. Bassani, ${ }^{2}$ and A. Tuissi ${ }^{2}$ \\ ${ }^{1}$ Department of Mechanical Engineering, Politecnico di Milano, Via La Masa, 20156 Milano, Italy \\ ${ }^{2}$ Institute for Energetics and Interphases, National Research Council (CNR), Corso Promessi Sposi, 23900 Lecco, Italy
}

Correspondence should be addressed to A. Lo Conte, antonietta.loconte@polimi.it

Received 6 August 2012; Revised 21 November 2012; Accepted 28 November 2012

Academic Editor: Hideki Hosoda

Copyright ( $) 2012$ M. Bocciolone et al. This is an open access article distributed under the Creative Commons Attribution License, which permits unrestricted use, distribution, and reproduction in any medium, provided the original work is properly cited.

\begin{abstract}
A new design of a $\mathrm{Cu}$ based SMA/GFRP lateral horn of a railway collector is proposed. Synergistic contribution of the performance parameters associated with the SMA, including specific damping, specific stiffness, and volume fraction, as well as those associated with the host composite such as flexural rigidity, SMA through-the-thickness location, and SMA-host interfacial strength, is taken into account. The aim is to increase the structural damping of the first flexural mode of the horn without significantly changing its flexural stiffness and weight. The focus of this work also applies to manufacturability and the cost effectiveness of the component for future industrial production.
\end{abstract}

\section{Introduction}

When considering high-speed railway current collection (Figure 1(a)), the dynamic interaction between the collectors (Figure 1(b)) and the contact wire for frequencies $>40$ $50 \mathrm{~Hz}$ is an issue in which collector deformable modes can play an important role. The contributions of these deformable modes superimpose the dynamic interaction between pantograph and catenary in the range of lowmedium frequencies $(0.5-20 \mathrm{~Hz})$. The measurement of the contact force during laboratory tests conducted on the dynamic behaviour of the pantograph identified a strong relationship between the contact loss percentage and the acceleration of a portion of the collector [1]. The influence of collector deformability on the dynamic interaction between the collectors and the contact wire was also confirmed through wind tunnel tests [2], as shown in Figure 2 where the spectral analysis of the contact force measured during a runup and run-down test on a complete pantograph is reported. The contribution of the flexural modes of the collector can be clearly identified at $60 \mathrm{~Hz}$ and $137 \mathrm{~Hz}$, corresponding to the first and third flexural vibrating modes of the collector. Moreover, the acoustic radiation from the collector is also inherently influenced by collector deformability, as reported in [3].
In order to guarantee a higher stability of the contact forces between collector and contact wire, it is necessary to increase the structural damping of the collector of the pantograph. A higher structural damping of the collector, than the actual one, is likely to reduce the amplitude of its dynamic vibration, thereby improving the quality of current collection. As a consequence of the reduction of the amplitude of the vibration of the pantograph, the acoustic radiation of the pantograph-catenary system should also be reduced. In a previous paper [4], we established that a possible way of increasing the modal damping of the flexural mode of the collectors, without radically modifying the structure of the collector, was to increase the specific damping of the lateral horns, whose primary function is to prevent an irregular positioning of the contact wire with respect to the collector. In a collector structure, a solution for enhancing damping based on the choice of high damping materials for the horns can be beneficial and less complex than the introduction of an active damping system. In particular, a configuration of a shape memory alloy (SMA) hybrid composite material like the one reported in $[5,6]$ can allow for the tailoring and optimization of density, flexural stiffness, and passive structural damping of the horn material. The aim of the renewed design of the 


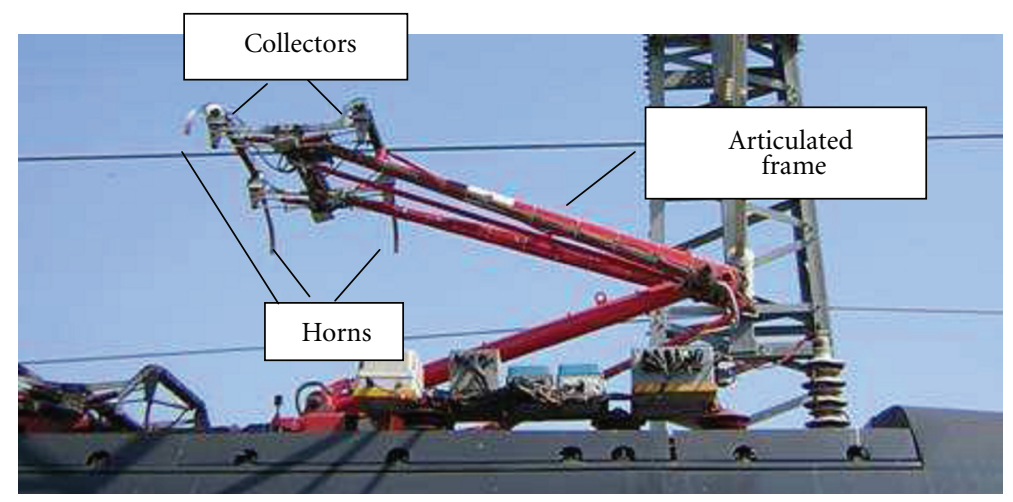

(a)

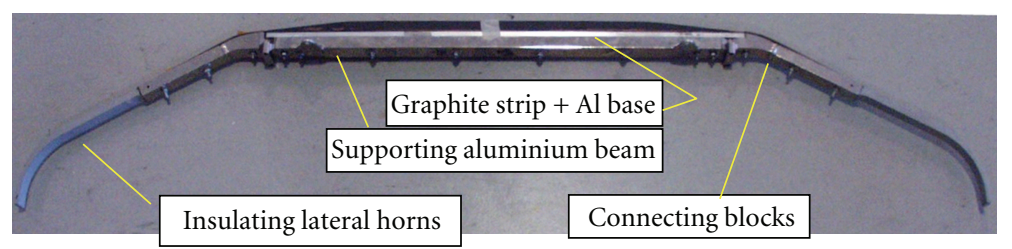

(b)

FIgURE 1: (a) High-speed pantograph in contact with the catenary. (b) Architecture of the collector.

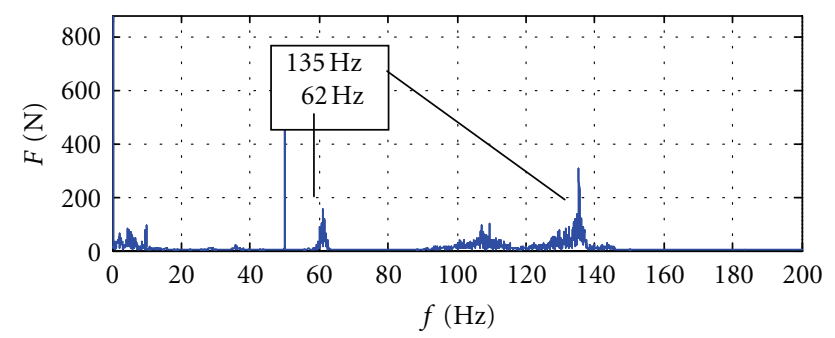

Figure 2: Contribution of deformable collector modes to the spectrum of the contact force related to the effect of incident flow: wind tunnel measurement results.

horn should duplicate its flexural damping without affecting its natural frequencies. Since the concept of SMA hybrid composites was first proposed in 1988 by Rogers et al. [7], these composites have attracted enormous attention in terms of improving creep and fatigue properties [8], strength [9], and damping capacity [10], as well as to control the shape or vibration response property [11]. Among these materials, the SMA/glass-fiber reinforced plastic (GFRP) hybrid composite-in which the embedded SMA is used to improve structural damping, thereby saving weight and stiffness, is especially important due to the wide potential or effective technological application of GFRP in all, real-life engineering environments $[12,13]$.

Shape memory alloys are characterized by two phases: an austenitic phase, obtained at high temperatures and a martensitic one, obtained at low temperatures; the direct and reverse phase transformation between the two phases occurs in a certain temperature range, depending on the composition and heat treatment of the alloy [14]. High damping can be observed during direct and reverse transformations, and, consequently, during limited temperature intervals. Several types of shape memory alloys, such as Cu based SMAs, show high values of internal friction, even in the martensitic state [15-17].

The fairly high intrinsic damping of these martensitic phases has been associated with the atoms and defect motion and with the reorientation of the martensite twin variants under stress [18]. From a practical point of view, this intrinsic energy dissipation mechanism of the martensitic phase over wider temperature ranges offers an interesting perspective for the application of SMA alloys in the martensitic state as passive dampers of low amplitude mechanical vibrations for automotive, aerospace, and other dynamic applications $[19,20]$. The idea of adopting the damping properties of the martensitic state means that the service temperature has to be lower than the transformation temperature.

The high cost, the relatively high specific weight, and the relatively low specific modulus preclude the use of monolithic SMA as a bulk material in many structures; however, interesting examples of composites or hybrid composites, designed for damping, can be found in the literature $[21,22]$.

\section{Design Consideration}

The original horn is made of unidirectional GFRP. Its first natural frequency, when mounted in the collector, is $60 \mathrm{~Hz}$ and the strain amplitude experienced during the mechanical vibration is in the range of $10^{-3}-10^{-4}$. The service temperature can be assumed to be in the range $-20 /+40^{\circ} \mathrm{C}$. In order to have a significant effect on the damping of the entire collector, our aim is to at least double the structural damping of the horn with respect to the original configuration.

The design and manufacture of a lateral horn in SMA/GFRP, boasting a high damping performance, while 
retaining the original geometrical configuration and saving the original weight and stiffness can be an interesting challenge and require consideration and selection of a significant number of characteristic and geometrical parameters. These include the use of SMA materials, a hybrid composite architecture, an SMA cross-sectional profile and dimension, and a GFRP layout.

When dealing with the intrinsic damping capacity of the martensite phases, the most widely studied and best-known systems are NiTi (nitinol), CuAlNi, and CuZnAl alloys [18].

In [23], thanks to the high damping of the NiTi in its martensitic state and transformation temperatures which are higher than the service temperatures of the horns, the authors proposed the application of Ti-Ni SMA alloy wires as "smart fibers" embedded in this conventional GFRP material in order to create new horns with an enhanced flexural damping capacity related to the first flexural mode. Two series of 13 wires, with a diameter of $0.56 \mathrm{~mm}$, were embedded below the upper and the lower surfaces of the horn as shown in Figure 3.

A first prototype of the horn was manufactured and then tested dynamically in a laboratory. Experimental results showed that not only do the NiTi wires collaborate in the composite but also that the nondimensional damping of the first flexural mode increases by about $11 \%$ with respect to the nondimensional damping of the original horn made only of GFRP. Conversely, the first natural frequency increases by about $5 \%$. According to these results, it can be expected that the higher level of the vibration damping, required for real application of the proposed architecture of the horn, can be obtained with a proper volume fraction of the SMA wires; however, the conflicting consequences of the introduction of SMA wires between increasing of the structural damping and increasing of the first natural frequencies are addressed. For this reason, the same paper also discusses the implementation of an FE model of the horn in order to perform a dynamic analysis and to calculate the related nondimensional damping. The results are presented for three configurations: the horns in their original configuration (only GRFP), the horns made from GRRP with two series of 13 embedded wires, as in the real prototype shown in Figure 3, and the horn made from GRRP with two series of 20 embedded wires. As expected, by increasing the number of wires, the vibration damping of the horn increases; however, the undesirable side effect of the NiTi wires is that the flexural frequency increases by $10 \%$, thus indicating that the requirements of the renewed design cannot be satisfied. Additionally, some consideration should also be given to the architecture of the lateral horn with embedded SMA wires. The manufacturing process involved in positioning the wires within the matrix is very complex. Furthermore, when the horn is cooled to room temperature, high residual stresses in the SMA wires are expected, due to the mismatch between the thermal expansion coefficients of the SMA material and the laminated GFRP composite. As a consequence, SMA fiber pullout can easily occur [11].

In this paper, the information generated and the experience gained in our previous paper will be used to propose the new design of an SMA/GFRP lateral horn, thanks

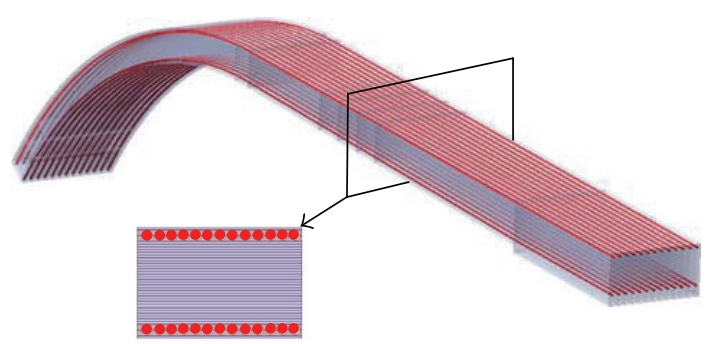

FIGURE 3: Lateral horn made from a GFRP laminated composite (light blue) with two layers of embedded NiTi wires (red).

to a synergistic contribution of the parameters associated with the SMA material such as specific damping, specific stiffness, and volume fraction as well as those associated with the host, including flexural rigidity, SMA throughthe-thickness location, and SMA-host interfacial strength. Particular attention will also be paid to manufacturability and the cost effectiveness of the component for future industrial production.

\section{SMA Material}

A CuZnAl alloy was selected as an SMA material because it has the highest damping capacity of all high damping metals [16] as well as a relatively high and appropriate modulus of elasticity; furthermore, it is compatible with the cure temperature of the GFRP host composite. Moreover, as shown in a recent study, composition, heat treatment, and quenching rates [10] can be optimized to reduce grain size, to improve workability of the alloy and to avoid intergranular fracture.

The CuZnAl alloy was prepared by means of a vacuum induction melting system. The nominal atomic composition of the SMA produced is $\mathrm{Cu}_{66} \mathrm{Zn}_{24} \mathrm{Al}_{10}$. The ingots were hot forged and hot and cold rolled to achieve sheets boasting a thickness of $0.3 \mathrm{~mm}(30-\mathrm{mm}$ in width and $400-\mathrm{mm}$ in length). The final heat treatment was performed at $750^{\circ} \mathrm{C}$ for $30 \mathrm{~min}$ and then water quenched (WQ).

The transformation temperatures were measured by means of a differential scanning calorimeter (DSC,-TA Instrument mod. Q100), calibrated with a standard indium reference. Specimens, weighing about $10 \mathrm{mg}$, were scanned at a heating/cooling rate of $10^{\circ} \mathrm{C} / \mathrm{min}$ within the temperature range $\left(10 / 110^{\circ} \mathrm{C}\right)$. The thermographs shown in Figure 4 outline the characteristic transformation temperatures: $M_{f}=$ $50^{\circ} \mathrm{C}, M_{s}=63^{\circ} \mathrm{C} ; A_{s}=60^{\circ} \mathrm{C}$, and $A_{f}=68^{\circ} \mathrm{C}$. The DSC scan confirms the martensitic structure in the temperature range of interest. Figure 5 shows the stress-strain curve in the martensitic state. Measurements were taken using DMA, mod. Q800, TA Instruments, in tensile mode under strain control at $30^{\circ} \mathrm{C}$. Samples, measuring $15 \mathrm{~mm}$ in width and $20 \mathrm{~mm}$ in length were cut with the axis in the rolling direction of the strip.

The damping properties of the alloy were evaluated by means of dynamic mechanical analyses. The instruments and the geometry of the samples are the same as those used for the tensile test. In this case, the specimen was subjected to 


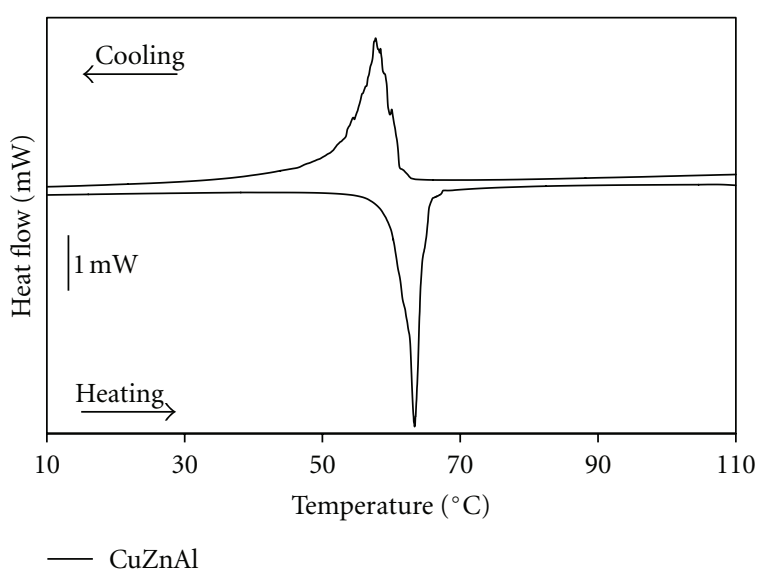

FIGURE 4: DSC scan, heating/cooling rate: $10^{\circ} \mathrm{C} / \mathrm{min}$.

a sinusoidal strain $(\varepsilon)$ with an amplitude of $0.01 \%, 0.05 \%$, and $0.1 \%$ and to a oscillation frequency $(f)$ of $2,10,20$, and $35 \mathrm{~Hz}$. The storage module $\left(E^{\prime}\right)$ and the phase lag $(\delta)$ between the applied stress and the resultant strain were measured in the temperature range $\left(-20^{\circ} \mathrm{C} / 120^{\circ} \mathrm{C}\right)$ with a cooling/heating rate of $1^{\circ} \mathrm{C} / \mathrm{min}$. As a result, the intrinsic damping $(\tan \delta)$ of the SMA was obtained as a function of the temperature.

Figure 6 shows the intrinsic damping $\tan \delta$ as a function of temperature for a $0.05 \%$ strain amplitude, at a $10 \mathrm{~Hz}$ frequency. The high damping capacity of the martensite phase can be observed at temperatures of below $60^{\circ} \mathrm{C}$ while, at higher temperatures, the parent phase (austenite phase) exhibits low $\tan \delta$ values. Damping increases when the strain amplitude increases; on the contrary, the storage modulus decreases with strain amplitude. No significant influence of frequency was observed in the range $(2 / 35 \mathrm{~Hz})$ tested. As a means of comparison, in Figure 6, we also show the low damping coefficient tan $\delta$ of commercial brass samples.

Owing to the fact that only a few grains were present in the cross-section of the DMA specimens, results were validated through cyclic stress strain tests on larger samples.

An MTS quasi-static testing machine with a load cell of $10 \mathrm{kN}$ is used for cyclic tension tests, at room temperature, on specimens measuring $200 \times 20 \mathrm{~mm}^{2}$. The cycle frequency is fixed as equal to $0.05 \mathrm{~Hz}$, based on the assumption that the SMA damping properties do not vary significantly at low frequencies.

A series of 16 tests were performed by controlling the cyclic elongation using a $50 \mathrm{~mm}$ gage length extensometer. The deformation amplitude ranges between $2 \times 10^{4}$ and $1 \times$ $10^{3}$, while the minimum value is about $3 \times 10^{4}$. In each test, 10 cycles were run at the specified deformation amplitude. The following parameters can be calculated at each strain amplitudes:

(1) $\tan \delta_{i}$ value, obtained from the single cycle as

$$
\tan \delta_{i}=\frac{\Delta W_{i}}{2 \pi W_{i}},
$$

where $\Delta W_{i}$ is the energy dissipated in the $i$ th cycle of oscillation for unit volume, representing the area

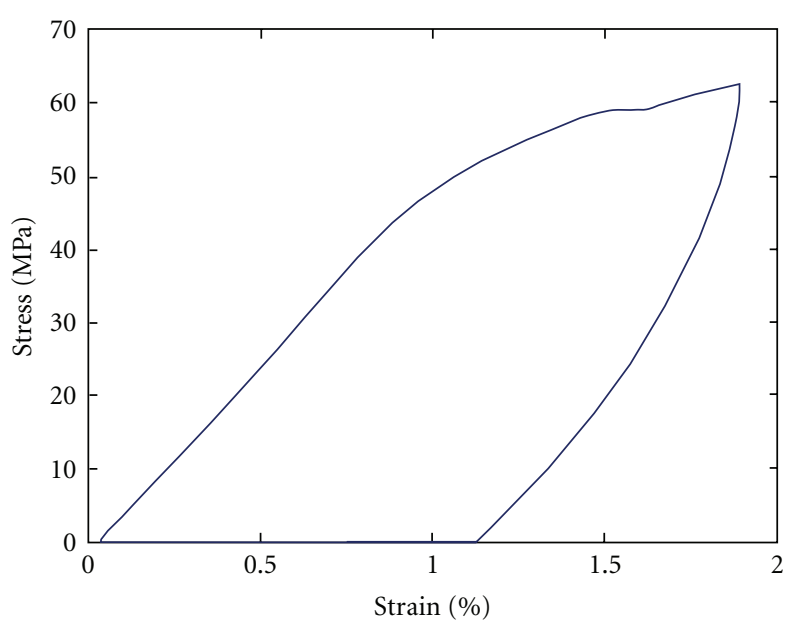

- CuZnAl

Figure 5: Stress-strain curve in the martensitic state at $30^{\circ} \mathrm{C}$.

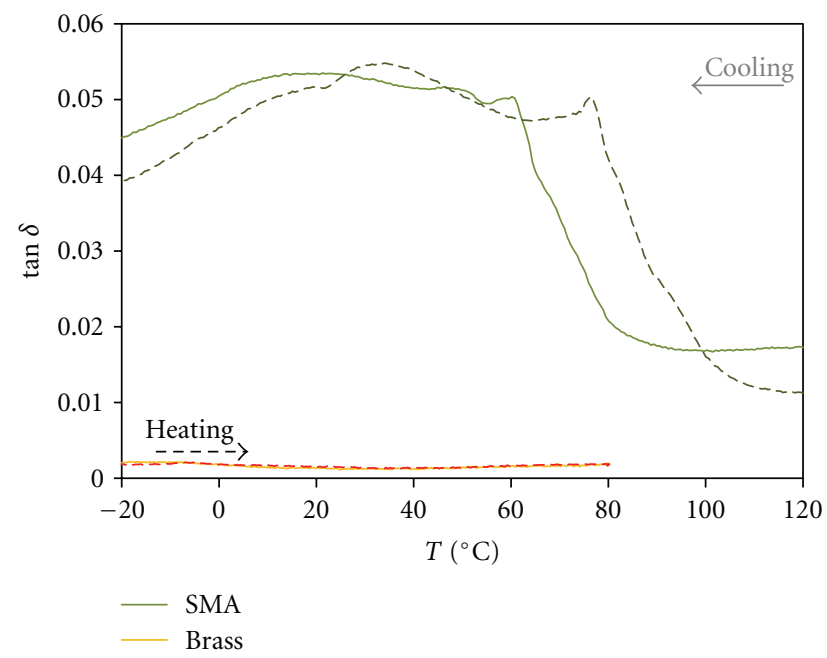

FIgURE 6: $\tan \delta$ versus temperature. DMA analysis: heating rate $1{ }^{\circ} \mathrm{C} / \mathrm{min}$, frequency $10 \mathrm{~Hz}$, and strain amplitude $0.05 \%$.

enclosed within the stress-strain hysteresis loop, and $W_{i}$ is the maximum stored energy in the same cycle of oscillation per unit volume;

(2) storage modulus $E_{i}$, evaluated as $\Delta \sigma / \Delta \varepsilon$ from the $i$ th hysteresis loop;

(3) SMA specific damping capacity $\tan \delta$ and SMA storage modulus, obtained as the average values over the ten stress-strain loops performed.

The results are shown in Figures 7 and 8. The loss factor shows an almost linear increase of the damping as a function of the strain amplitude, with a nonlinear increase at about $0.06 \%$ of strain. By comparison with Figure 6, a good agreement with DMA results, obtained at a frequency of $10 \mathrm{~Hz}$, can be observed. As shown by the results of DMA analysis, the storage modulus decreases as the strain amplitude increases. $\tan \delta$ discontinuity at a $0.05 \%$ strain amplitude was observed during a tensile test, also performed 


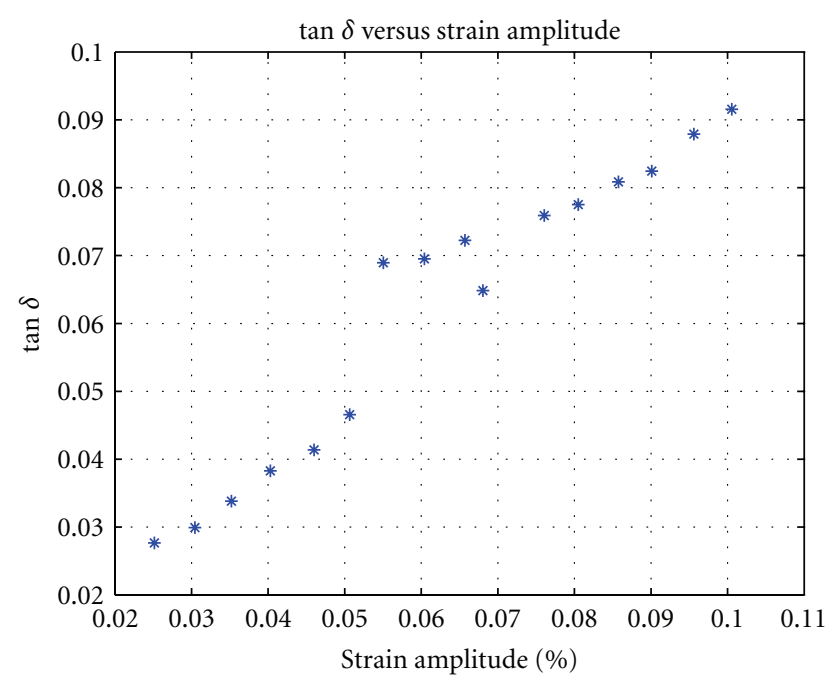

Figure 7: $\tan \delta$ versus strain amplitude. Tensile test: frequency $10 \mathrm{~Hz}$, room temperature.

by means of an MTS configuration on the entire sample. This confirms that this particular trend of $\tan \delta$ is associated with a certain behaviour of the Cu based SMA. In order to understand this phenomenon better, accurate experiments will be performed in future developments: However, in this case, since it is not the main topic of this paper, it has not been taken into consideration.

\section{Hybrid Composite Architecture}

As shown in Figure 9, a new architecture of an SMA/GFRP hybrid composite profile, previously investigated by the authors [10], is proposed for the design of an SMA/GFRP lateral horn.

The hybrid composite is made from GFRP laminates and is reinforced with two thin sheets of SMA.

The two SMA sheets are embedded in a sandwich-like structure between the bulk and the external layers of the cross section of the horn. The SMA was chosen in sheet form not only due to the fact that, in practice, it is much simpler to embed in the host GFRP composite but also because it does not require the use of special fixture jigs, thus increasing flexibility during the manufacturing process. At the same time, not only is the manufacturing process involved in making the lateral horn simpler, but it can also make use of the same dies and mould used for the GFRP horns, thus saving extra costs and time.

The host composite is a symmetric angle-ply laminate of fiber glass/epoxy resin (E300-Glass EC9) with a stacking sequence of $(45 /-45)_{n}$, where $n$ varies, thus accounting for the variation in the horn thickness, ranging from 49 (thicker section) to 24 at the opposite end.

The thin SMA sheets are laser patterned in order to improve adhesion between the SMA inserts and the GFRP laminated composite, to avoid delamination of the hybrid composite and to maximize the load transfer between the GFRP laminated composite and the SMA reinforcements (Figure 10).

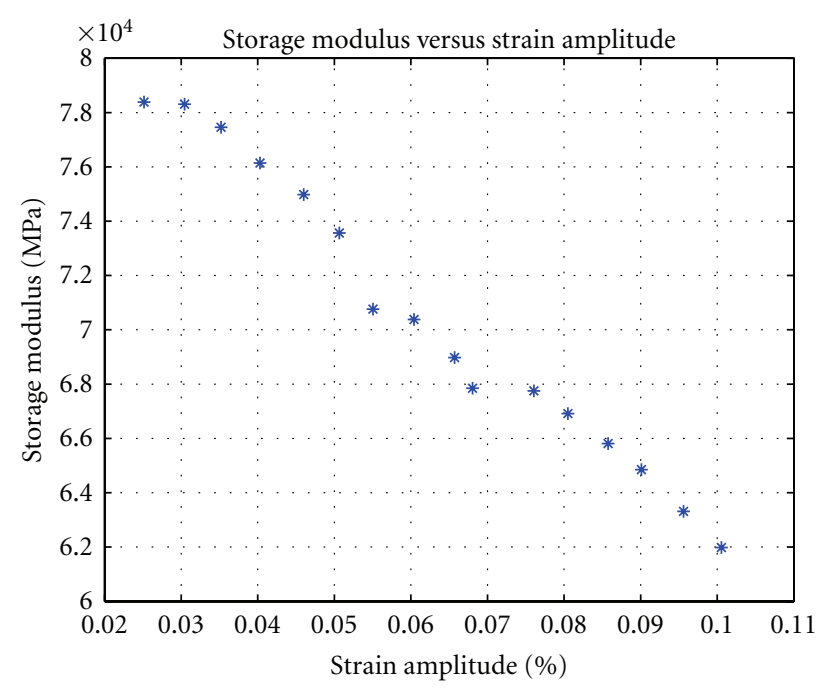

Figure 8: Storage modulus versus strain amplitude. Tensile test: frequency $10 \mathrm{~Hz}$, room temperature.

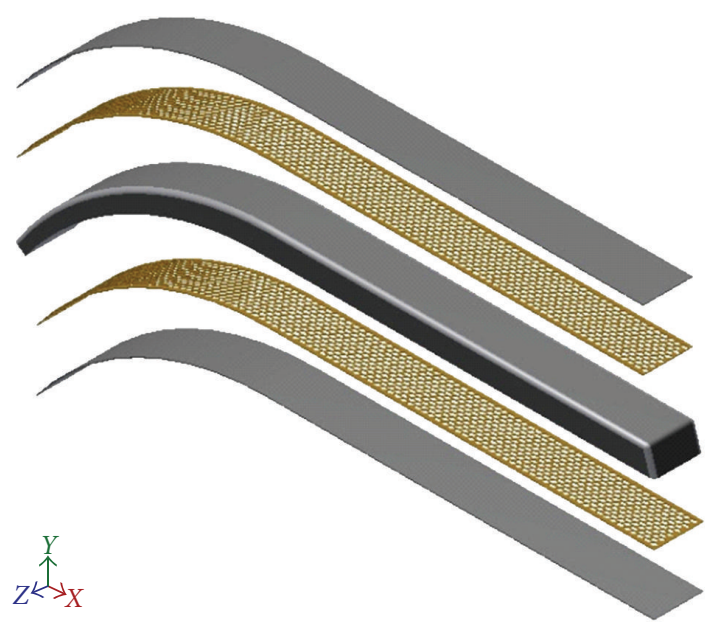

FIGURE 9: Architecture of the SMA//GFRP hybrid composite horn. Grey $[-45 /+45]_{n}$ layered GFRP host composite. Brown: embedded $\mathrm{CuZnAl} \mathrm{SMA} \mathrm{thin} \mathrm{patterned} \mathrm{sheets.}$

The geometry of the patterning, the ratio between the surface of the holes, and the total surface of the SMA sheet, just like the thickness of the sheets, were optimized on a hybrid SMA/GFRP composite having both the same architecture of the horn shown in Figure 9 and comparable sizes [10]. This increase is not, however, obtained to the detriment of the flexural stiffness and weight of the host composite. Consequently, both the natural frequency and dynamic behaviour are preserved.

According to these previous studies, an elliptical pattern, having a ratio equal to 1.32 between the surface of the holes and the total surface of the SMA sheet, as well as a sheet thickness equal to $0.3 \mathrm{~mm}$, was selected for the present application.

As regards the thickness effect, it is necessary to point out that the composite loss factor increases with the thickness of the SMA sheets. On the other hand, technological 


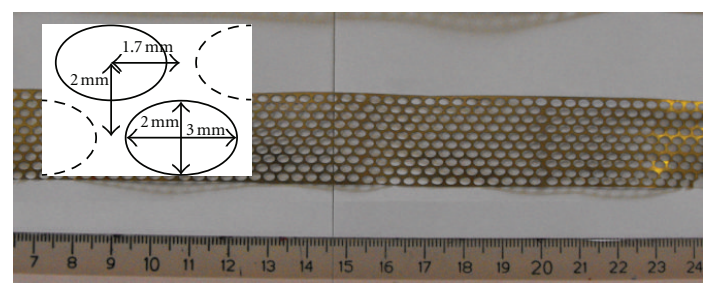

Figure 10: $\mathrm{CuZnAl}$ sheets after laser microcutting.

aspects related to the laser microcutting process have to be considered when the sheet thickness used in the layered composite is increased. Laser microcutting becomes more difficult when the thickness is significantly increased owing to the fact that the process speed has to be reduced and a multipass strategy adopted. Both actions decrease the cutting edge quality in terms of dross, roughness, and thermal damage. Since finishing operations, targeted at removing the layer affected by the laser beam are intentionally disregarded because they increase process costs and time, a thickness of $0.3 \mathrm{~mm}$ seems to be a better compromise between damping and workability of the SMA sheet [23].

\section{Manufacture Process}

The manufacturing process involved in making the horn is divided into two steps. Firstly, the regular pattern of elliptical holes was produced by means of laser cutting using a pulsed nanosecond fiber laser (IPG Photonics YLP50). The process parameters used to perform the microcutting process of the elliptical pattern are shown in Table 1.

The maximum average power available, together with the highest pulse frequency and process speed, was chosen to ensure through cutting and reduced thermal damage. A double laser pass strategy was required in order to guarantee stable cutting through the entire thickness of the SMA sheet [24].

In the second step, the laminated composite is assembled. The horn mould is filled first with four layers $(+45 /-45)_{4}$ of unidirectional fiber glass/epoxy resin and covered with the first patterned thin SMA sheet; the sequence of lamination $(+45 /-45)_{n}$ is added and covered by the second thin SMA sheet and by an additional four layers $(+45 /-45)_{4}$ of unidirectional fiber glass/epoxy resin. As previously reported, parameter $n$ is dependent on the thickness of the cross section along the axis of the horn. Any air bubbles are eliminated by means of a vacuum bag and the hybrid composite is then cured in an autoclave.

In order to study the dynamic properties of the proposed hybrid layered architecture and to evaluate the improvement of the damping capacity due to the introduction of the SMA insert, three samples of the horn were produced. The first one was manufactured as described, while the second one was produced using the same architecture as the first one. However, in this case, commercial brass sheets were used in the place of the SMA sheets. The third one was only made with GFRP. Manufacture of an extra horn with a commercial brass insert is targeted at evaluating/excluding any possible
TABLE 1: Main process parameters used in laser microcutting of the elliptical pattern.

\begin{tabular}{lccc}
\hline $\begin{array}{l}\text { Process speed } \\
(\mathrm{mm} / \mathrm{s})\end{array}$ & $\begin{array}{c}\text { Average power } \\
(\mathrm{W})\end{array}$ & $\begin{array}{c}\text { Pulse frequency } \\
(\mathrm{kHz})\end{array}$ & Shielding gas \\
\hline 5 & 50 & 80 & $\begin{array}{c}\text { Argon at } \\
5 \text { bar }\end{array}$ \\
\hline
\end{tabular}

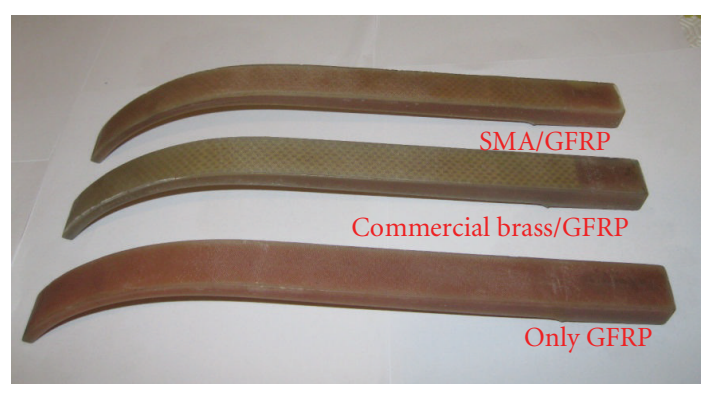

FIgURE 11: Final appearance of the three horn samples.

contribution of a metal sheet/host composite interface to the damping of the SMA hybrid composite horn. As shown in Figure 11, following the cure cycle in an autoclave, the three horn samples are completed.

\section{Experimental Setup and Procedure}

As shown in Figure 12, the nondimensional damping, related to the first flexural mode of the three horns manufactured, was experimentally measured by performing a series of decay tests with the horn in a single cantilever configuration.

During the tests, the end of the horn, designed to be connected to the structure of the collector, was clamped on a steel fixture, while the other end was loaded with an initial vertical displacement and then released to oscillate freely [22]. The transient response was recorded in terms of the vertical displacement of the section of the horn at a distance of $150 \mathrm{~mm}$ from the clamp. The displacement was measured by means of a lase-triangulation sensor (MEL M5L/10).

The nondimensional damping was evaluated as follows:

$$
h_{n}=\frac{\delta_{n}}{2 \pi}, \quad \text { where } \delta_{n}=\ln \left(\frac{x_{n}}{x_{n+1}}\right)
$$

where $\delta_{n}$ is the logarithmic attenuation coefficient, $x_{n}$ is the vertical displacement amplitude of the horn at $150 \mathrm{~mm}$ from the clamping at the $n$th oscillation of the transient response, and $x_{n+1}$ is the same displacement amplitude at the $(n+1)$ th oscillation. During transient decay, the amplitude of each successive oscillation decreases, meaning that (2) allows us to obtain the dependence of the nondimensional damping from the displacement amplitude.

In order to compare the nondimensional damping $(h)$ with the loss factor $(\tan \delta)$, assumed as an index of the intrinsic damping in Section 2, the following consideration can be made. 


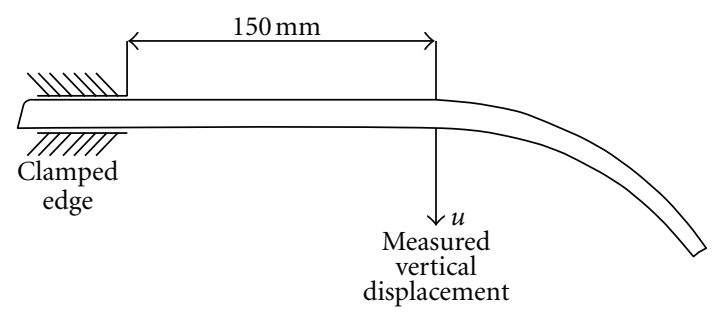

FIGURE 12: Schematic diagram of the single cantilever experimental setup.

The loss factor $(\tan \delta)$ of the oscillatory beam, considered as a single degree of freedom system, is defined as the ratio

$$
\tan \delta=\frac{E_{d}}{2 \pi U},
$$

where $E_{d}$ is the energy loss per cycle and $U$ is the strain energy.

Assuming that the motion is entirely due to the first flexural mode

$$
\begin{gathered}
U=\frac{1}{2} k_{1} q_{1}^{2}, \\
E_{d}=\pi \cdot c_{1} \omega_{1} q_{1}^{2},
\end{gathered}
$$

where $k_{1}$ is the modal stiffness, $q_{1}$ is the modal coordinate, $c_{1}$ is the modal damping, and $\omega_{1}$ is the frequency of the first flexural mode of the beam.

On account of $k_{1}=m_{1} \omega_{1}^{2}$, where $m_{1}$ is the modal mass of the beam and, from the definition of nondimensional damping $c_{1}=h_{1}\left(2 m_{1} \omega_{1}\right)$, (3) can be rewritten as:

$$
\tan \delta=\frac{\pi \cdot c_{1} \omega_{1} q_{1}^{2}}{2 \pi(1 / 2) k_{1} q_{1}^{2}}=\frac{h_{1}\left(2 m_{1} \omega_{1}\right) \omega_{1} q_{1}^{2}}{\pi m_{1} \omega_{1}^{2} q_{1}^{2}}=2 h .
$$

Equation (6) recalls that the loss factor is equal to twice the nondimensional damping value.

\section{Results and Discussion}

The natural frequency of vibration of the first flexural mode can be identified by Fourier transform of the waveform of the transient response of the horns acquired during the decay tests reported in Figure 13. In this figure, the transient response of the horn with a commercial brass patterned insert is actually superimposed on the only GFRP horn and, for sake of clarity, is not reported. The first natural frequencies of the three horn samples are shown in Table 2 and are not affected by the integration of the SMA/commercial brass. The total weight of the horns is also reported in the same table and is only slightly affected by the integration of the SMA/commercial brass. As will be shown below, the reduced thickness of the SMA/commercial brass sheets and the patterns with a ratio between the surface of the holes and the total surface of the SMA sheet, equal to 1.32 , allows us not only to maintain the structural and dynamic behaviour of the component but also to improve the damping capacity.
TABLE 2: First natural frequency and total weight of the three horn samples.

\begin{tabular}{lcc}
\hline & $\begin{array}{c}\text { First natural } \\
\text { frequency }(\mathrm{Hz})\end{array}$ & $\begin{array}{c}\text { Total weight } \\
\text { of the horn }(\mathrm{g})\end{array}$ \\
\hline Only GFRP & 75.5 & 168 \\
Commercial brass/GFRP & 75.3 & 182 \\
SMA/GFRP & 74.8 & 180 \\
\hline
\end{tabular}

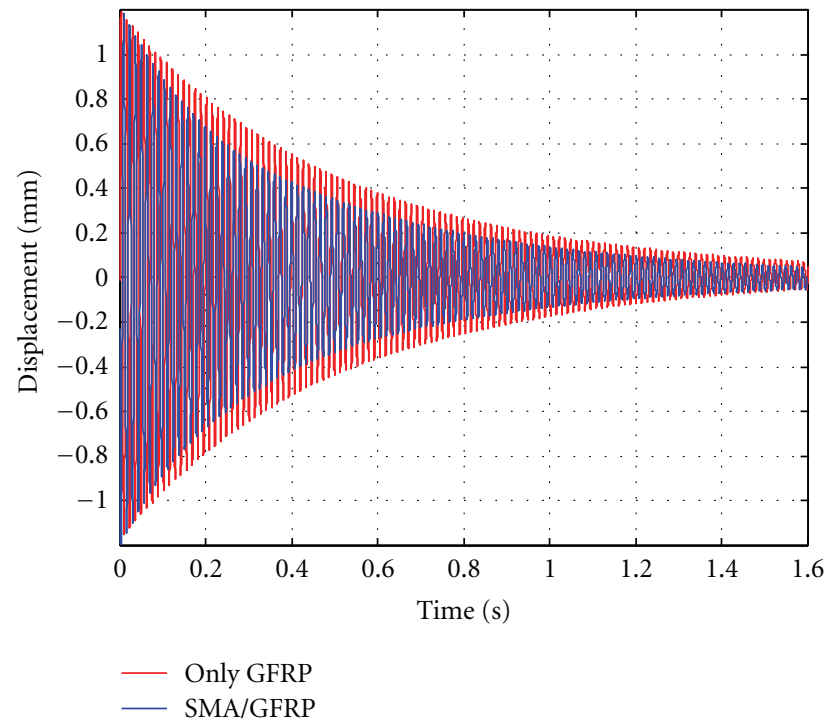

Figure 13: Transient of the displacement in the section at $150 \mathrm{~mm}$ from the clamped section, for the horn with an SMA patterned insert and for the horn made only from GFRP.

The beneficial effect of the integration of an SMA insert in the host GFRP horn on its damping capacity is apparent in Figure 13.

The horn manufactured as an SMA/GFRP hybrid composite has a larger logarithm attenuation coefficient of the first flexural mode both as regards the horn made only from GFRP as well as the one manufactured as a commercial brass/GFRP hybrid composite. As previously mentioned in Figure 13, the transient response of the latter two is practically superimposed.

The results of experimental nondimensional damping, associated with the first flexural mode, calculated from the logarithmic decrement over each period of Figure 13, are shown in Figure 14. In this figure, the range of the vertical displacement amplitude, decreasing from left to right, is between the maximum value measured which is equal to $1.2 \mathrm{~mm}$ and to $0.4 \mathrm{~mm}$; the curve related to the decay tests of the commercial brass/GRFP horn is also added for the sake of comparison.

As expected, the nondimensional damping of the only GFRP sample is constant with the level of vibration. This value is taken as the reference value to estimate the improvement of the damping due to the use of the SMA material. Furthermore, the nondimensional damping of the Commercial brass/GFRP horn is almost constant with the level of vibration and, only at the beginning of the transient, 


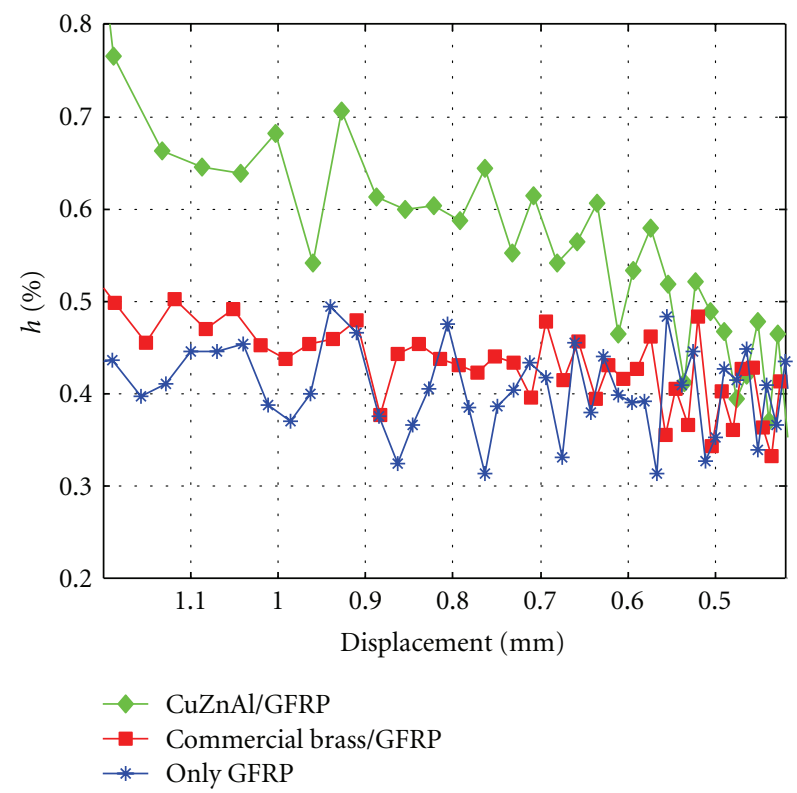

Figure 14: Nondimensional damping $h$ related to the first flexural frequency of the horn obtained from the decay response test.

slightly higher than the glass fiber value. This comparison allows us to exclude any significant contribution of the metal sheet/host composite interface to the damping of the SMA hybrid composite horn.

When the SMA patterned sheets are embedded in the composite, the nondimensional damping is significantly enhanced. As expected, enhancement of the damping of the SMA/GFRP hybrid composite is higher for large vibration amplitudes, while decreasing for lower vibration amplitudes. This result is due to the amplitude dependency of the intrinsic damping of the SMA sheets (Figure 7). When the vertical displacement amplitude becomes small (about $0.5 \mathrm{~mm}$ in Figure 13), the average strain experienced by the SMA along the axis of the horn decreases, and the related intrinsic damping factor ( $\tan \delta$ of Figure 7 ) becomes closer to the intrinsic damping value of the Only GFRP horn. Therefore, at these low displacement amplitudes, the structural damping of the SMA/GFRP hybrid composite tends towards the structural damping of the glass fiber without any embedded layer.

\section{Conclusions}

A new design of a GFRP lateral horn of a railway pantograph was proposed:

(i) a new hybrid composite architecture was adopted;

(ii) a laminated GFRP was used as the host composite, while a CuZnAl SMA alloy was the high damping material used for the reinforcement;

(iii) the SMA alloy was embedded in the shape of two patterned thin sheets between the bulk and external layers of the cross section of the horn.

The pattern of the thin SMA sheets proved to be a key feature in the optimization process of the flexural stiffness, weight, and damping capacity of the horn. At the same time, this feature plays a positive role in the improvement of adhesion, and in the load transfer, between the GFRP laminated composite and the SMA reinforcements.

In the strain amplitude range equal to $10^{-4} / 10^{-3}$, the structural damping of the horn was significantly enhanced, and, in accordance with the initial requirements, the geometrical configuration of the horn, its flexural stiffness, and its weight were retained.

A first prototype of the horn was manufactured. The salient points of the manufacturing process included the production of a CuZnAl SMA alloy having an appropriate transformation temperature; the laser micro-cutting of the CuZnAl SMA sheets, and the absence of any purpose-made alignment device.

\section{Acknowledgment}

The authors would like to thank Mako Shark Srl, 18, 23843 Dolzago (LC), Italy, for the manufacture of the laminated horns.

\section{References}

[1] A. Collina and S. Melzi, "Effect of contact strip-contact wire interaction on current transfer at high sliding speed in the mid-high frequency range," in Proceedings of the 5th International Conference on Tribology (AITC-AIT '06), Parma, Italy, September 2006.

[2] A. Collina, F. Resta, D. Rocchi, and A. Tosi, "Analisi dei fenomeni aerodinamici dell'interazione pantografo-catenaria (Analysis of the aerodynamic phenomena in pantographcatenary interaction)," in Proceedings of the 9th Convegno Nazionale di Ingegneria del Vento (IN-VENTO '06), Pescara, Italy, June 2006.

[3] E. Pfinzenmaier, W. F. King, and D. Christ, "Untersuchung zur aerodynamischen und aeroakustischen Optimierung eines Stromabnehmer für den ICE,” AET, no. 49, 1985.

[4] A. Collina, A. Lo Conte, and M. Carnevale, "Effect of collector deformable modes in pantograph-catenary dynamic interaction," Proceedings of the IMechE Part F: Journal of Rail and Rapid Transit, vol. 223, no. 1, pp. 1-14, 2009.

[5] R. X. Zhang, Q. Q. Ni, A. Masuda, T. Yamamura, and M. Iwamoto, "Vibration characteristics of laminated composite plates with embedded shape memory alloys," Composite Structures, vol. 74, no. 4, pp. 389-398, 2006.

[6] K.-T. Lau, L.-M. Zhou, and X.-M. Tao, "Control of natural frequencies of a clamped-clamped composite beam with embedded shape memory alloy wires," Composite Structures, vol. 58, pp. 39-47, 2002.

[7] C. A. Rogers, C. Liang, and D. Barker, "Control concepts using shape memory alloy reinforced plates," in Proceedings of the US Army Research Office Workshop on Smart Materials, Structures, and Mathematical Issues, p. 39, Blacksburg, Va, USA, 1988.

[8] M. Dolce and D. Cardone, "Fatigue resistance of SMAmartensite bars subjected to flexural bending," International Journal of Mechanical Sciences, vol. 47, no. 11, pp. 1693-1717, 2005.

[9] D. S. Li, X. P. Zhang, Z. P. Xiong, and Y. W. Mai, "Lightweight NiTi shape memory alloy based composites with high damping capacity and high strength," Journal of Alloys and Compounds, vol. 490, no. 1-2, pp. L15-L19, 2010. 
[10] C. A. Biffi, P. Bassani, A. Tuissi et al., "Flexural vibration suppression of glass Fiber/CuZnAl SMA composite," Functional Materials Letters, vol. 5, no. 1, Article ID 1250014, 4 pages, 2012.

[11] G. Zhou and P. Lloyd, "Design, manufacture and evaluation of bending behaviour of composite beams embedded with SMA wires," Composites Science and Technology, vol. 69, no. 13, pp. 2034-2041, 2009.

[12] Y. Matsuzaki, T. Ikeda, and C. Boiler, "New technological development of passive and active vibration control: analysis and test," Smart Materials and Structures, vol. 14, no. 2, pp. 343-348, 2005.

[13] F. Taheri-Behrooz, F. Taheri, and R. Hosseinzadeh, "Characterization of a shape memory alloy hybrid composite plate subject to static loading," Materials and Design, vol. 32, no. 5, pp. 2923-2933, 2011.

[14] K. Otsuka and C. M. Wayman, Shape Memory Materials, Cambridge University Press, Cambridge, UK, 199.

[15] A. Biscarini, B. Coluzzi, G. Mazzolai, F. M. Mazzolai, and A. Tuissi, "Mechanical spectroscopy of the H-free and H-doped Ni30Ti50Cu20 shape memory alloy," Journal of Alloys and Compounds, vol. 356-357, pp. 669-672, 2003.

[16] M. O. Moroni, R. Saldivia, M. Sarrazin, and A. Sepúlveda, "Damping characteristics of a CuZnAlNi shape memory alloy," Materials Science and Engineering A, vol. 335, no. 1-2, pp. 313-319, 2002.

[17] Y. H. Li, S. W. Liu, H. C. Jiang et al., "Analysis of the internal friction spectrum of TiNiCu alloy," Journal of Alloys and Compounds, vol. 430, no. 1-2, pp. 149-152, 2007.

[18] J. Van Humbeeck, "Damping capacity of thermoelastic martensite in shape memory alloys," Journal of Alloys and Compounds, vol. 355, no. 1-2, pp. 58-64, 2003.

[19] J. Van Humbeeck and S. Kustov, "Active and passive damping of noise and vibrations through shape memory alloys: applications and mechanisms," Smart Materials and Structures, vol. 14, no. 5, pp. S171-S185, 2005.

[20] J. Raghavan, T. Bartkiewicz, S. Boyko, M. Kupriyanov, N. Rajapakse, and B. Yu, "Damping, tensile, and impact properties of superelastic shape memory alloy (SMA) fiberreinforced polymer composites," Composites B, vol. 41, no. 3, pp. 214-222, 2010.

[21] Y. Xu, K. Otsuka, H. Yoshida et al., "A new method for fabricating SMA/CFRP smart hybrid composites," Intermetallics, vol. 10, no. 4, pp. 361-369, 2002.

[22] R. X. Zhang, Q. Q. Ni, A. Masuda, T. Yamamura, and M. Iwamoto, "Vibration characteristics of laminated composite plates with embedded shape memory alloys," Composite Structures, vol. 74, no. 4, pp. 389-398, 2006.

[23] A. Tuissi, P. Bassani, R. Casati et al., "Application of SMA composites in the collectors of the railway pantograph for the italian high-speed train," Journal of Materials Engineering and Performance, vol. 18, no. 5-6, pp. 612-619, 2009.

[24] S. Arnaboldi, P. Bassani, C. A. Biffi et al., "Microcutting of niticu alloy with pulsed fiber laser," in Proceedings of ASME 10th Biennial Conference on Engineering Systems Design and Analysis (ESDA '10), pp. 593-602, Istanbul, Turkey, July 2010. 

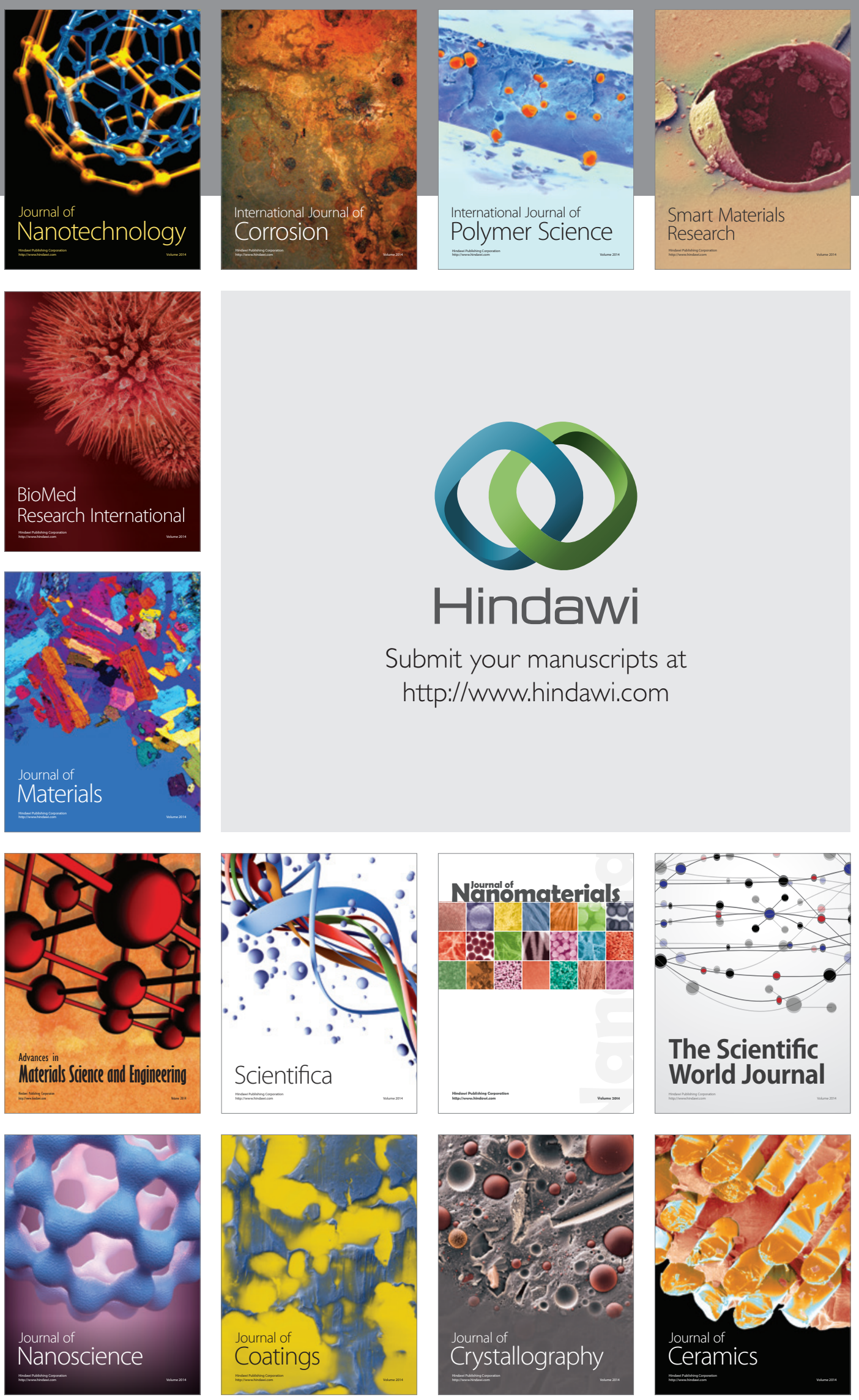

The Scientific World Journal

Submit your manuscripts at

http://www.hindawi.com

\section{World Journal}

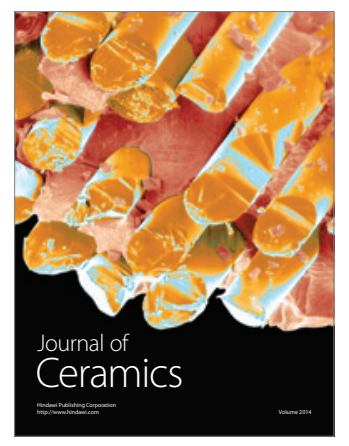

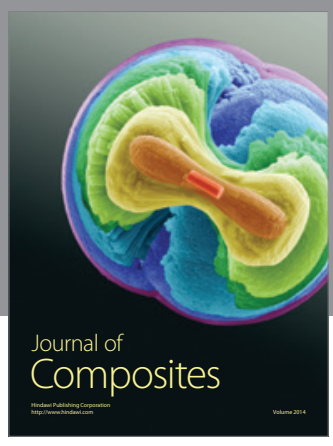
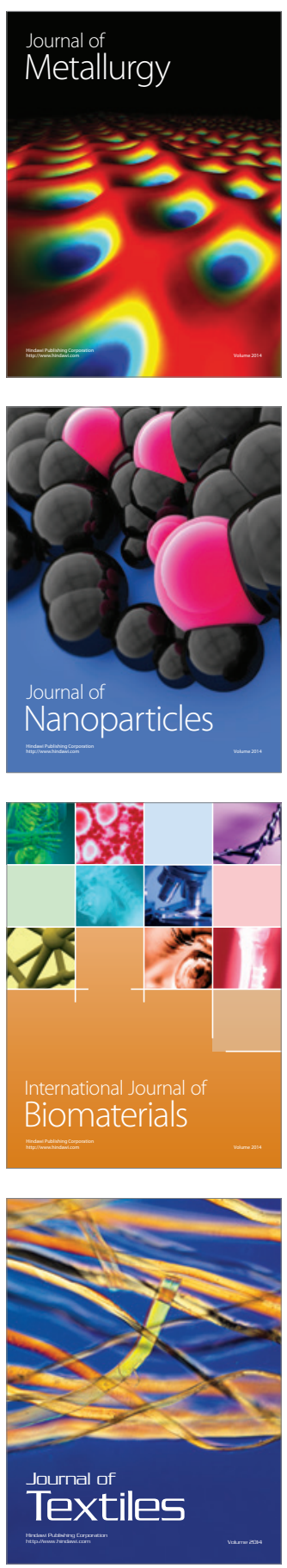